\title{
Association between dynamic obesity and mortality in patients with first-ever ischemic stroke: a hospital-based prospective study
}

\section{Ju Wang}

west china school of public health and west china fourth hospital, sichuan university

Jijie Li

Sichuan University West China Second University Hospital

\section{Mier Li}

West China School of Public Health and west china fourth hospital, sichuan university

\section{Lisha Hou}

Sichuan University West China Hospital

\section{Ping Zhu}

Sichuan University West China Hospital

\section{Xudong Du}

Sichuan University West China School of Public Health

\section{Muke Zhou}

Sichuan University West China Hospital

Cairong Zhu ( $\nabla$ cairong.zhu@hotmail.com )

https://orcid.org/0000-0001-6795-582X

\section{Research article}

Keywords: Obesity, time-dependent, paradox, ischemic stroke, mortality

Posted Date: May 14th, 2019

DOI: https://doi.org/10.21203/rs.2.9579/v1

License: (c) (1) This work is licensed under a Creative Commons Attribution 4.0 International License.

Read Full License

Version of Record: A version of this preprint was published at Medicine on September 18th, 2020. See the published version at https://doi.org/10.1097/MD.0000000000022243. 


\section{Abstract}

Background and Purpose: Although obesity is an established risk factor for the occurrence of a primary stroke, the association between obesity with post-stroke mortality remains unclear. We evaluated the association of dynamic obesity status with mortality among first-ever stroke survivors in China. Methods: Data from 775 patients with first-ever ischaemic stroke from a longitudinal study, 754 patients were categorized 4 categories of BMI (underweight, normal weight, overweight and obese) and 2 categories of WC (normal WC and abdominal obesity) according to Chinese-specific criteria. Mortality information and obesity status were obtained through every 3 months via telephone follow-up, beginning in 2010 and continuing through 2016. Chi-square tests were used to compare different obesity status at admission and personal characteristics. Time-dependent Cox proportional hazards models were used to estimate the unadjusted and adjusted hazard ratios (HRs) for relationship between all-cause mortality and dynamic obesity status. Results: Of 754 analyzed patients, $60.87 \%$ were males, with a mean age of 61.45 years. After adjusting for possible confounders, there were significant inverse associations between BMI and WC with all-cause mortality: compared with normal BMI or WC counterparts, overweight and abdominal obesity patients significantly decrease risk of all-cause mortality (HR and $95 \%$ confidence interval (Cl):0.521 $(0.303,0.897), 0.545(0.352,0.845)$,respectively), whereas under-weight patients have the highest risk and obese have decreased risk of mortality, though significance was not obtained $(1.241(0.691,2.226), 0.486(0.192,1.231)$, respectively). Conclusions: Overweight and abdominal obesity was paradoxically associated with reduced risk of mortality among first-ever ischaemic stroke survivors in China. Body weight management recommendations ought to not be based on mere projection from primary prevention of stroke.

\section{Background}

Obesity is an established risk factors for primary stroke in general population[1]. Accordingly, for primary preventive purpose of stroke, there is general agreement to recommend striving for a normal weight[2]. However, the lastest guidelines for secondary prevention refer that the beneficial effect of reducing weight is still uncertain[3]. Moreover, the association of obesity with mortality among stroke patients remains controversial. Some findings thought obesity worsen prognosis in stroke survivor[4,5], while others think obesity confer better survival $[2,6]$. Numerous findings indicated that in contrast to that of the general population, there exist an inverse relationship between obesity and mortality in stroke survivor, which is termed as obesity paradox[7]. Therefore, it is unclear if recommendations derived from primary prevention should be extended to secondary prevention of cardiovascular disease.

However, those studies that explored the association between obesity and stroke outcomes, exist some vital limited. Therefore, the results remains to be confirmed. It is well known, however, that the assumption that obesity status remained constant during follow-up was unreasonable, which may make obesity status misclassified and thus obtain biased results. Furthermore, it is noteworthy that mounting studies obtaining obesity paradox, failed to fully consider confounders associated with all-cause 
mortality in post-stroke patients, e.g. the stroke severity has not been quantified and treatment of stroke was ignored[2, 5], which may contribute a false impression that obesity constitutes a survival advantage.

So whether the phenomena that obesity has been associated with better prognosis after stroke is true or just biased by imperfect confounder adjustment or research method? Should maintaining a normal weight still be advised if overweight or obesity carry a more favorable prognosis? To our best of knowledge, there are few studies simultaneously using BMI and WC to describe the obesity status in stroke patients from general and abdominal obesity aspects and few studies considering dynamic obesity status. Moreover, limited studies explored the relationship between obesity and post-stroke mortality among Chinese population, a subgroup with high prevalence rates of obesity and stroke[8,9]. Therefore, our study attempts to explore the association between dynamic obesity status and mortality among first-ever ischaemic stroke survivors in China.

\section{Methods}

\section{Study Population}

The study was launched among first-ever ischaemic stroke survivors in the Department of Neurology, West China Hospital. A patient was diagnosed with stroke, according to the WHO criteria[10]. Stroke subtype (cerebral hemorrhage or infarction) is determined following computed tomography (CT) or magnetic resonance imaging (MRI). Patients with cardiovascular surgery, such as carotid endarterectomy, cardiac surgery or angiography, which may induce stroke, were excluded.

Written informed consents were obtained from all patients or their designated relatives. The study protocol was approved by the Ethics Committee of West China Hospital, Sichuan University, Chengdu, China.

\section{Study Design}

A semi-structured questionnaire was used to conduct face-to-face interview at the hospital by professionally trained, qualified and experienced interviewers. Combined the questionnaire with medical records, demographic characteristics, lifestyle, vascular risk factors and stroke severity were considered to examine the influences on post-stroke mortality. Demographic characteristics included gender, age ( $<45,45 \sim 64$ and $>65$ years), civil status (with spouse, without spouse), occupation (farmer, nonagricultural laborer, retired, unemployed), education attainment ( $\leq 6,7$ to 9 and $\geq 10$ years), household income $(<3057.4,3057.4 \sim 6114.8,>6114.8 \$$ per year), number of resident population in their family ( $<3$, $3 \sim 4,>4$ persons). Lifestyle aforementioned includes smoking status (never smoking, smoking cessation, current smoking, passive smoking), drinking status (never or current drinking), pre-stroke exercise time $(<210,210 \sim 420$ and $>420$ minutes per week). Vascular risk factors, included family history of stroke, hypertension, diabetes mellitus (DM), hyperlipidemia, heart disease and peripheral vascular diseases. Diagnosis of aforementioned co-morbidities is made following their current standards[11, 12]. 


\section{Measure of obesity}

Because most patients were unable to stand on admission, it is difficult to directly measure height, weight and WC. At baseline, participants were asked to report their weight, height and WC by answering the following questions: "What is your weight now?" in $\mathrm{kg}$ and to the nearest $0.1 \mathrm{~kg}$, "What is your height and waist circumference?" in $\mathrm{cm}$ and to the nearest $0.1 \mathrm{~cm}$. Body weight status was measured by BMI calculated from height and weight (weight in kilograms divided by height in meters squared). These subjects were divided into four subgroups according to the Chinese criteria: underweight $(\mathrm{BMl}<18.5$ $\mathrm{kg} / \mathrm{m}^{2}$ ), normal weight ( BMI 18.5 to $<24 \mathrm{~kg} / \mathrm{m}^{2}$ ), overweight ( $\mathrm{BMl} 24$ to $<28 \mathrm{~kg} / \mathrm{m}^{2}$ ) and obese $(\mathrm{BMl} \geq 28$ $\left.\mathrm{kg} / \mathrm{m}^{2}\right)[13]$. $W C \geq 85 \mathrm{~cm}$ in men and $W C \geq 80 \mathrm{~cm}$ in women were used to indicate abdominal obesity according to the Chinese-specific WC cutoff points of modify International Diabetes Federation criteria $[14,15]$.

\section{Outcomes and Follow-up}

Follow-up was routinely conducted via telephone interviews every 3 months by trained and qualified investigators after hospital discharge. The follow-up survey included the information on the severity of the stroke, body weight, WC, anti-thrombotic medication adherence and heath outcome. Because most patients are in acute phase in baseline survey and stroke severity changes quickly, mRS scores in baseline survey may not accurately reflect the stroke severity[16], hence the mRS score at the first time of follow-up was deemed to indicate stroke severity instead. mRS score $<2$ was defined as mild disability, while $\mathrm{mRS}$ score $\geq 3$ was defined as severe/moderate disability[17]. Patient strictly according with the doctor's advice to take, change or quit anti-thrombotic medication during the follow-up period is termed as adherence, and vice versa. The endpoint of the study is all-cause mortality, which was got from patients' relatives when follow-up. Survival time was from baseline survey to death from any cause, withdraw or end of follow up. Follow up continued until the patients dropped out of the study, died or could no longer be contacted.

\section{Statistical Analysis}

Descriptive statistics on baseline individual characteristics were stratified by baseline obesity status assessed by BMI and WC with Chi-square test or Fisher exact test. We used change in obesity status updated every 3 months as a time-varying exposure, and time-dependent Cox proportional hazard regression model $[18,19]$ was used to estimate the hazard ratio $(\mathrm{HR})$ for all-cause mortality in the followed-up. Statistical tests were two-sided and $P$ value of $<0.05$ were considered statistically significant. All statistical analyses were performed using the SAS 9.3 (SAS Institute Inc., Cary, NC, USA).

\section{Results}

During January 2010 and June 2016, there were 775 subjects enrolled. After excluding 21 patients (2.7\%) with repeated recruited and missing data, a total of 754 patients were included in our analysis. The mean age of those was 61.45 years (range, $17-89$ years) and $60.88 \%$ were male. Analyzed patients were 
followed-up for a mean period of 54.86 months (range, 0-75 months). Overall, baseline demographic and clinical characteristics are shown in Table 1.

At admission, $33.69 \%$ of patients were categorized as overweight, $10.08 \%$ as obese, $45.62 \%$ as abdominal obesity, and the survival curve was significantly different among different subgroups in Figure 1 and 2 . Univariate analysis results are shown in Table 2.

Results of multivariable-adjusted time-dependent Cox proportional hazards regression analysis on BMI and WC subgroups are shown in table 3 and 4 . When adjusted only for age, overweight remained associated with decreased mortality (HR: $0.491,95 \%$ Cl: $0.293,0.824)$; in univariate analysis, severity of stroke was strongly associated with post-stroke mortality and after we adjusted it, results alter slightly. Similarly, after simultaneous adjustment for all socio-demographic and other factors in table 2, an inverse relationship between $\mathrm{BMI}$ and all-cause mortality was constantly observed in overweight (HR: $0.521 ; 95 \%$ Cl. 0.303-0.897). Particularly, underweight counterparts had the worst survival all the time in any of adjusted model, but significances still were not obtained. Notably, for obese subjects, the statistical significance was lost after adjusted for any of listed confounders. After simultaneous adjustment for all aforementioned factors, the significant association between mortality and obesity still wasn't observed (HR: 0.487; 95\% Cl: 0.192-1.235).

Furthermore, with respect to threshold categories for WC, the inverse association was constantly observed, in any considered model. Simultaneous adjustment for all characteristics, mortality risk were significantly lower in the abdominal obesity patients compared with normal WC (HR: $0.572 ; 95 \% \mathrm{Cl}$ : 0.370-0.883).

\section{Discussion}

The main finding of present study is that patients hospitalized for ischaemic stroke who are overweight and obese have better survival when compared with normal weight participators. In contrast, underweight patients show the worst mortality. It's noteworthy, that the inverse associations of body weight and outcome measures remained after adjustment for confounder. Furthermore, the inverse association between abdominal obesity and mortality was constantly observed.

The results of this study are in line with studies showing that overweight group significantly decrease risk of mortality[20,21]. When omitting different covariate from our models, risk of mortality among overweight participants was still lower. Similarly, Vemmos et al[21]. revealed that overweight significantly confer better survival rates compared to those with normal BMI. Contrastively, inconsistent with our finding, Dehlendorff et al.[22] have suggested overweight was not associated with decreased risk of allcause mortality. The possible reason is that both ischaemic stroke and hemorrhagic stroke survivors were included in Dehlendorff's, while our study only included the former. Another possible explanation for distinct result is that our participants were followed-up for a mean period of 54.86 months and endpoint is all-cause mortality, which differs from Dehlendorff's assessed deaths caused by the index stroke at 1 week and 1 month. 
Furthermore, our findings revealed that obesity confer decreased risk of mortality without statistical significance, which is consistent with other findings[23, 24]. A Chinese follow-up study[25], have found obesity (27.5-32.4 kg/m $\left.{ }^{2}\right)$ isn't associate with increased risk, which is similar to the South Korea result of Ryu et al[24]. However, a TEMPiS study[6] revealed lowest mortality risk was observe in obese and very obese patients when compared with normal BMI counterparts. The discrepancy of the findings may be due to several reasons. Firstly, the TEMPiS study was a non-randomized intervention study comparing acute stroke treatment and without specialized stroke care in hospitals, differently ours was hospitalbased longitudinal study without any intervention. Secondly, the TEMPiS study included individuals with hemorrhagic stroke, whereas our study included only first-ever ischaemic stroke subjects. So, the relationship between obesity and all-cause mortality still remain to be validated.

A remarkable finding in our study was that abdominal obesity also associated with better prognosis in stroke patients, which was in accordance with results from previous studies[26]. Though currently subjects were divided into normal WC and abdominal obesity according to all sex-specific WC criteria, which couldn't distinguish mild, moderate and extreme abdominal obesity. However, Gomes et al.[26] used quartiles of WC to categorize different levels of abdominal obesity, found $4^{\text {th }}$ quartile WC confer significant better survival, while $3^{\text {rd }}$ and $2^{\text {nd }}$ decreased risk of mortality without significance, when compared with $1^{\text {st }}$ quartile WC.

The obesity paradox should not be directly interpreted as the fatter the better. Although the obesity paradox has been confirmed in various chronic diseases, such as cancer, hypertension and DM[27-29]. There are some proposed explanations for the paradox. Firstly, obese patients may tend to present earlier/more aggressive treatment, varying the natural history of their disease, which may have benefited from lead-time bias[23]. Meanwhile, obese counterparts were encouraged to change unhealthy lifestyle [2] and thereby acquired a better prognosis, but this requires additional research. Additionally, underweight may be the result of another underlying disease, unintentional weight loss, reduced mental and physical health or severe comorbidities that lead to worse prognosis[30, 31].

Several strengths and limitations should be acknowledged and discussed. Our strength is that we have considered association not only general obesity but also abdominal obesity with mortality in a long-term Chinese cohort. Furthermore, in our study, important confounding factors, such as stroke severity and anti-thrombotic medication adherence, have been comprehensively considered, but often absent in previous studies[2, 5]. Importantly, the dynamic change of weight and WC in the period of follow-up has been considered by recording temporary $\mathrm{BMI}$ and WC in every follow-up, which may constitute believable conclusion.

Our study does have some limitations. Firstly, weight, height and WC were indicated by self-report of patients other than tool measuring, which may be biased[32]. However, previous studies have suggested that self-reported weight, height and WC have satisfactorily accurate for the assessment of the obesity status and have near-perfect correlations and agreement with measured anthropometric values[33, 34]. Furthermore, BMI failed to distinguish between individuals with different types of fat distribution[35] and 
WC unable to distinguish persons with different height[36]. However, directly and accurately quantified methods are impractical and time-consuming[37]. Therefore, self-reported data should be generally acceptable.

Moreover, index bias may exist in our study, because though in our study all possible confounding were considered, essentially no uncontrolled confounding of both the obesity and mortality is impossible[38]. Even though unmeasured confounder inevitable, index bias only may be a partial explanation of the obesity paradox, which can't deny obesity paradox does exists in stroke survivors[39]. Finally, our participants were recruited only from West China Hospital of Sichuan University, which might limit the generalized ability of these findings.

\section{Conclusions}

Overweight and abdominal obesity was paradoxically associated with reduced risk of mortality among AIS survivors in China. Consequently, we certifies body weight management recommendations in AIS survivors ought to not be based on mere projection from primary prevention of stroke. Further studies are required to devise such a weight management strategies for optimal prognosis in secondary prevention among stroke survivors.

\section{Abbreviations}

AIS: acute ischemic stroke; BMI: Body Mass Index; WC: Waist circumference

\section{Declarations}

\section{Ethics approval and consent to participate}

Written informed consents were obtained from all patients or their designated relatives. The study protocol was approved by the Ethics Committee of West China Hospital, Sichuan University, Chengdu, China.

\section{Competing interests}

The authors declare that they have no competing interests.

\section{Authors' contributions}

JW and JL was involved in design of the study, data collection, interpretation of the data and writing and revising the manuscript. $\mathrm{CZ}$ and $\mathrm{MZ}$ took part in design of the study, funding obtained, data collection, interpretation of the data and revising the manuscript. ML and LH were involved in data collection. XD 
and PZ took part in data analysis and revising the manuscript. All authors read and approved the final manuscript.

\section{Acknowledgements}

This work was supported by National Natural Science Foundation of China (grant no. 81673273 and 30600511).The analyses and interpretations of the data and the final content of the article were produced independently of the financial sponsors. We thank all participants in this study.

\section{Author details}

${ }^{1}$ Department of Epidemiology and Biostatistics, West China School of Public Health and West China fourth Hospital, Sichuan University, Chengdu, Sichuan 610044, P.R. China. ${ }^{2}$ Institution of West China Second University Hospital, Sichuan University, Chengdu, Sichuan 610044, P.R. China. ${ }^{3}$ Department of Neurology, West China Hospital of Sichuan University, Chengdu, Sichuan 610044, P.R. China.

\section{References}

1. Strazzullo P, D'Elia L, Cairella G, Garbagnati F, Cappuccio FP, Scalfi L. Excess Body Weight and Incidence of Stroke. Stroke. 2010;41 5:e418-26.

2. Andersen KK, Olsen TS. The obesity paradox in stroke: lower mortality and lower risk of readmission for recurrent stroke in obese stroke patients. International journal of stroke : official journal of the International Stroke Society. 2015;10 1:99-104; doi: 10.1111/ijs.12016.

3. Meschia JF, Bushnell C, Bodenalbala B, Braun LT, Bravata DM, Chaturvedi S, et al. Guidelines for the Primary Prevention of Stroke: A Statement for Healthcare Professionals From the American HeartAssociation/American Stroke Association. Stroke. 2014;45 12:3754.

4. Karri S, Per T, Finn R. Weight status in young adulthood and survival after cardiovascular diseases and cancer. International journal of epidemiology. 2014;43 4:1197-204.

5. Silventoinen K, Tynelius P, Rasmussen F. Weight status in young adulthood and survival after cardiovascular diseases and cancer. International journal of epidemiology. 2014;43 4:1197-204; doi: 10.1093/ije/dyu091.

6. Doehner W, Schenkel J, Anker SD, Springer J, Audebert HJ. Overweight and obesity are associated with improved survival, functional outcome, and stroke recurrence after acute stroke or transient ischaemic attack: observations from the TEMPiS trial. Eur Heart J. 2013;34 4:268-77; doi: 10.1093/eurheartj/ehs340.

7. Mcauley PA, Blair SN. Obesity paradoxes. Journal of Sports Sciences. 2011;29 8:773-82. 
8. Wang W, Jiang B, Sun H, Ru X, Sun D, Wang L, et al. Prevalence, Incidence, and Mortality of Stroke in China. Circulation. 2017;135 8:759.

9. Tian $Y$, Jiang $C$, Wang $M$, Cai R, Zhang $Y$, Zhongtao $H$, et al. Body mass index, leisure-time physical activity and physical fitness in Chinese adults:a series of national surveys from 2000 to 2014. 2016.

10. Listed N. Stroke-1989. Recommendations on stroke prevention, diagnosis, and therapy. Report of the WHO Task Force on Stroke and other Cerebrovascular Disorders. Stroke; a journal of cerebral circulation. 1989;20 10:1407-31.

11. Kernan W, Ovbiagele B, Black H, Bravata D, Chimowitz M, Ezekowitz M, et al. Guidelines for the prevention of stroke in patients with stroke and transient ischemic attack: a guideline for healthcare professionals from the American Heart Association/American Stroke Association. Stroke. 2014;45 7:2160-236.

12. Liu LS. 2010 Chinese guidelines for the management of hypertension. Chinese Journal of Hypertension. 2011;39 2:579-615.

13. Department of disease control mohotPsRoC. Control guidelines for Chinese adult overweight and obesity. 1rd edn. People's Medical Publishing Hous; 2006.

14. Lu B, Yang Y, Song X, Dong X, Zhang Z, Zhou L, et al. An evaluation of the International Diabetes Federation definition of metabolic syndrome in Chinese patients older than 30 years and diagnosed with type 2 diabetes mellitus. Metabolism. 2006;55 8:1088-96; doi: 10.1016/j.metabol.2006.04.003.

15. Zhai Y, Zhao WH, Chen CM. Verification of the cut-off waist circumference for defining central obesity in Chinese adults. International journal of cardiology. 2009;137 2:S101-S.

16. Dong YH, Slavin MJ, Chan PL, Sharma VK, Crawford JD, Collinson SL, et al. Cognitive screening improves the predictive value of stroke severity scores for functional outcome 3-6 months after mild stroke and transient ischaemic attack: an observational study. Bmj Open. 2013;3 9:e003105.

17. van Swieten J, Koudstaal P, Visser M, Schouten H, van Gijn J. Interobserver agreement for the assessment of handicap in stroke patients. Stroke. 1988;19 5:604-7.

18. Andersen P, Gill R. Cox's Regression Model for Counting Processes: A Large Sample Study. 1982.

19. And LDF, Lin DY. Time-dependent covariates in the Cox proportional-hazards regression model. Annu Rev Public Health. 1999;20 1:145-57.

20. Bell CL, Lacroix A, Masaki K, Hade EM, Manini T, Mysiw WJ, et al. Prestroke factors associated with poststroke mortality and recovery in older women in the Women's Health Initiative. Journal of the American Geriatrics Society. 2013;61 8:1324-30.

21. Vemmos K, Ntaios G, Spengos K, Savvari P, Vemmou A, Pappa T, et al. Association between obesity and mortality after acute first-ever stroke: the obesity-stroke paradox. Stroke. 2011;42 1:30-6; doi: 10.1161/STROKEAHA.110.593434.

22. Dehlendorff C, Andersen KK, Olsen TS. Body mass index and death by stroke: no obesity paradox. JAMA neurology. 2014;71 8:978-84; doi: 10.1001/jamaneurol.2014.1017. 
23. Kawase S, Kowa H, Suto Y, Fukuda H, Kusumi M, Nakayasu H, et al. Association between body mass index and outcome in Japanese ischemic stroke patients. Geriatrics \& gerontology international. 2016;17 3:369-74; doi: 10.1111/ggi.12713.

24. Ryu WS, Lee SH, Kim CK, Kim BJ, Yoon BW. Body mass index, initial neurological severity and longterm mortality in ischemic stroke. Cerebrovascular diseases. 2011;32 2:170-6; doi: $10.1159 / 000328250$.

25. Zhao L, Du W, Zhao X, Liu L, Wang C, Wang Y, et al. Favorable functional recovery in overweight ischemic stroke survivors: findings from the China National Stroke Registry. Journal of stroke and cerebrovascular diseases : the official journal of National Stroke Association. 2014;23 3:e201-6; doi: 10.1016/j.jstrokecerebrovasdis.2013.10.002.

26. Gomes F, Emery PW, Weekes CE: Mortality and Stroke Recurrence in Obese Stroke Patients: The Obesity Paradox in a London-Based Population. In: International Stroke Conference. 2014.

27. Tseng $\mathrm{CH}$. Obesity paradox: differential effects on cancer and noncancer mortality in patients with type 2 diabetes mellitus. Atherosclerosis. 2013;226 1:186-92.

28. Uretsky S, Messerli FH, Bangalore S, Champion A, Cooperdehoff RM, Zhou Q, et al. Obesity paradox in patients with hypertension and coronary artery disease. American Journal of Medicine. 2007;120 10:863-70.

29. Gonzalez MC, Pastore CA, Orlandi SP, Heymsfield SB. Obesity paradox in cancer: new insights provided by body composition. American Journal of Clinical Nutrition. 2014;99 5:999-1005.

30. Whitlock, Lewington G, Sherliker S, Clarke P, Emberson R, Halsey J, et al. Body-mass index and causespecific mortality in 900000 adults: collaborative analyses of 57 prospective studies. Lancet. 2009;373 9669:1083-96.

31. Skolarus LE, Sanchez BN, Levine DA, Baek J, Kerber KA, Morgenstern LB, et al. Association of body mass index and mortality after acute ischemic stroke. Circulation Cardiovascular quality and outcomes. 2014;7 1:64-9; doi: 10.1161/CIRCOUTCOMES.113.000129.

32. Connor GS, Tremblay M, Moher D, Gorber B. A comparison of direct vs. self-report measures for assessing height, weight and body mass index: a systematic review. Obesity Reviews An Official Journal of the International Association for the Study of Obesity. 2007;8 4:307.

33. Reidpath DD, Cheah CH, Lam FC, Yasin S, Soyiri I, Allotey P. Validity of self-measured waist and hip circumferences: results from a community study in Malaysia. Nutrition Journal. 2013;12 1:1-5.

34. Ng SP, Korda R, Clements M, Latz I, Bauman A, Bambrick H, et al. Validity of self-reported height and weight and derived body mass index in middle-aged and elderly individuals in Australia. Australian \& New Zealand Journal of Public Health. 2011;35 6:557-63.

35. Okorodudu DO, Jumean MF, Montori VM, Romero-Corral A, Somers VK, Erwin PJ, et al. Diagnostic performance of body mass index to identify obesity as defined by body adiposity: a systematic review and meta-analysis. Int J Obes (Lond). 2010;34 5:791-9; doi: 10.1038/ijo.2010.5.

36. Rodeamontero ER, Eviaviscarra ML, Apolinarjiménez E. Waist-to-Height Ratio Is a Better Anthropometric Index than Waist Circumference and BMI in Predicting Metabolic Syndrome among 
Obese Mexican Adolescents. International Journal of Endocrinology. 2014;2014:195407.

37. Yamborisut U, Sakamoto N, Wimonpeerapattana W, Tontisirin K. Waist circumference and body fat distribution indexes as screening tools for the overweight and obesity in Thai preschool children. Obesity Research \& Clinical Practice. 2010;4 4:e307-e14.

38. Preston SH, Stokes A. Obesity paradox: conditioning on disease enhances biases in estimating the mortality risks of obesity. Epidemiology. 2014;25 3:454-61.

39. Sperrin M, Candlish J, Badrick E, Renehan A, Buchan I. Collider bias is only a Partial Explanation for the Obesity Paradox. Epidemiology. 2016;27 4:525-30.

\section{Tables}

Table 1. Epidemiologic characteristics, co-morbidities, and stroke severity by BMI and WC subgroup (at

admission) 


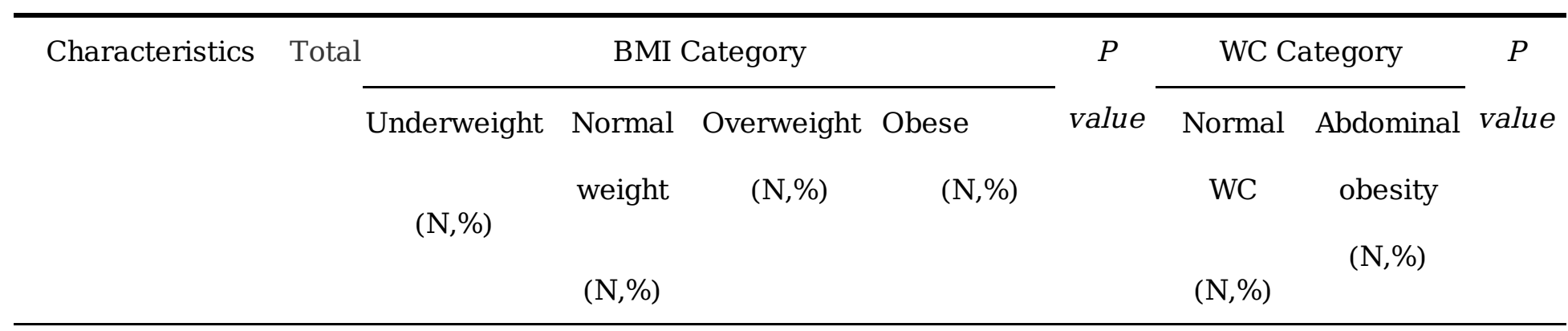

Number of

$754 \quad 49(6.50) \quad 375(49.73) \quad 254(33.69) \quad 76(10.08)$

$344(45.62) 410(54.38)$

participant $(\mathrm{N}, \%)$

Gender

\begin{tabular}{|c|c|c|c|c|c|c|}
\hline Male & 459 & $27(5.88)$ & $234(50.98)$ & 154(33.55) & $44(9.59)$ & $0.719218(47.49) 241(52.51)$ \\
\hline Female & 295 & $22(7.46)$ & $141(47.80)$ & $100(33.90)$ & $32(10.85)$ & $126(42.71) 169(57.29)$ \\
\hline
\end{tabular}

Age-group(year) ${ }^{*}$

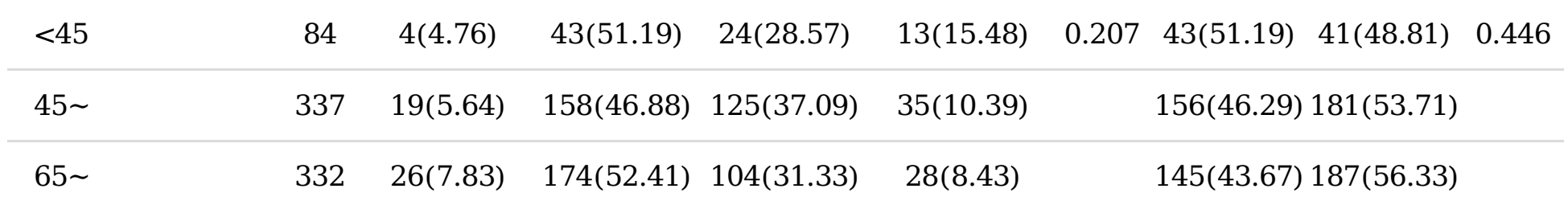

Civil status

\begin{tabular}{|c|c|c|c|c|c|c|c|c|}
\hline Without spouse & 96 & $12(12.50)$ & $51(53.13)$ & $22(22.92)$ & 11(11.46) & 0.016 & $43(44.79)$ & $53(55.21)$ \\
\hline With spouse & 658 & $37(5.62)$ & $324(49.24)$ & $232(35.26)$ & $65(9.88)$ & & $301(45.74)$ & $357(54.26)$ \\
\hline
\end{tabular}

Education

attainment(year) ${ }^{*}$

\begin{tabular}{|c|c|c|c|c|c|c|}
\hline$\leq 6$ & 285 & $26(9.12)$ & $142(49.82)$ & $89(31.23)$ & $28(9.82)$ & $0.364138(48.42) 147(51.58)$ \\
\hline 7 to 9 & 190 & $7(3.68)$ & $95(50.00)$ & $69(36.32)$ & $19(10.00)$ & $88(46.32)$ 102(53.68) \\
\hline$\geq 10$ & 275 & $16(5.82)$ & 135(49.09) & $96(34.91)$ & $28(10.18)$ & $115(41.82) 160(58.18)$ \\
\hline
\end{tabular}

Occupation* $^{*}$

\begin{tabular}{|c|c|c|c|c|c|c|c|c|c|}
\hline Farmer & 189 & $16(8.47)$ & $101(53.44)$ & $59(31.22)$ & $13(6.88)$ & 0.326 & $98(51.85)$ & $91(48.15)$ & 0.047 \\
\hline Non-agricultural & 203 & $10(4.93)$ & $101(49.75)$ & $66(32.51)$ & $26(13.30)$ & & $100(49.26)$ & $103(50.74)$ & \\
\hline
\end{tabular}

\begin{tabular}{|c|c|c|c|c|c|c|}
\hline Retired & 312 & $17(5.45)$ & $151(48.40)$ & 112(35.90) & $32(12.81)$ & $126(40.38) 186(59.62)$ \\
\hline Unemployed & 49 & $6(12.24)$ & $22(44.90)$ & 17(34.69) & $4(8.16)$ & $20(40.82) \quad 29(59.18)$ \\
\hline
\end{tabular}




\begin{tabular}{|c|c|c|c|c|c|c|c|c|c|}
\hline \multirow[t]{4}{*}{ Characteristics } & \multirow[t]{4}{*}{ Total } & \multicolumn{4}{|c|}{ BMI Category } & $P$ & \multicolumn{2}{|c|}{ WC Category } & $P$ \\
\hline & & Underweight & Normal & Overweight & Obese & value & Norma & Abdominal & value \\
\hline & & & weight & $(\mathrm{N}, \%)$ & $(\mathrm{N}, \%)$ & & WC & obesity & \\
\hline & & & $(\mathrm{N}, \%)$ & & & & $(\mathrm{N}, \%)$ & $(\mathrm{N}, \%)$ & \\
\hline
\end{tabular}

Household income

(dollars/year) $^{*}$

\begin{tabular}{|c|c|c|c|c|c|c|}
\hline$<3057.4$ & 252 & $22(8.73)$ & $129(51.19)$ & $83(32.94)$ & $18(7.14)$ & $0.451129(51.19) 123(48.81)$ \\
\hline 3057.4 to 6114.8 & 245 & $13(5.31)$ & $121(49.39)$ & $84(34.29)$ & $27(11.02)$ & $110(44.90) 135(55.10)$ \\
\hline$>6114.8$ & 237 & $14(5.91)$ & 113(47.68) & $83(35.02)$ & $27(11.39)$ & $96(40.51) 141(59.49)$ \\
\hline
\end{tabular}

Number of resident

population

\begin{tabular}{|c|c|c|c|c|c|c|}
\hline$<3$ & 359 & $27(7.52)$ & $182(50.70)$ & 118(32.87) & $32(8.91)$ & $0.780158(44.01) 201(55.99)$ \\
\hline 3 to 4 & 249 & $13(5.22)$ & 118(47.39) & $89(35.74)$ & $29(11.65)$ & 118(47.39) 131(52.61) \\
\hline$>4$ & 146 & $9(6.16)$ & $75(51.37)$ & $47(32.19)$ & $15(10.27)$ & $68(46.58)$ \\
\hline
\end{tabular}

Smoking status

\begin{tabular}{|c|c|c|c|c|c|c|}
\hline Non-smoking & 334 & $23(6.89)$ & $161(48.20)$ & 108(32.34) & $42(12.57)$ & $0.139144(43.11) 190(56.89)$ \\
\hline Passive smoking & 117 & $7(5.98)$ & $54(46.15)$ & $49(41.88)$ & $7(5.98)$ & $51(43.59) \quad 66(56.41)$ \\
\hline Smoking & 244 & $15(6.15)$ & $125(51.23)$ & $85(34.84)$ & $19(7.79)$ & $122(50.00) 122(50.00)$ \\
\hline
\end{tabular}

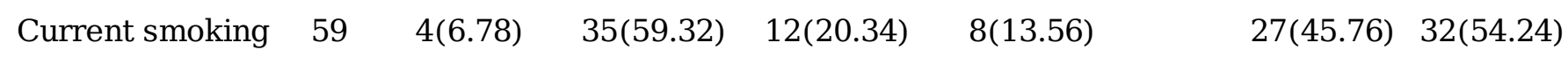

Drinking status

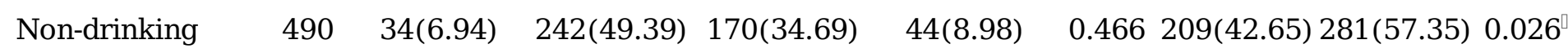

$\begin{array}{llllll}\text { Current drinking } & 264 & 15(5.68) & 133(50.38) & \text { 84(31.82) } & \text { 32(12.12) }\end{array}$

Pre-stroke exercise

time within a week

(minutes)

\begin{tabular}{|c|c|c|c|c|c|c|}
\hline$<210$ & 491 & $30(6.11)$ & 255(51.93) & $156(31.77)$ & $49(9.99)$ & $0.001229(46.64) 262(53.36)$ \\
\hline $210 \sim$ & 82 & $14(17.07)$ & $34(41.46)$ & $26(31.71)$ & $8(9.76)$ & $42(51.22) \quad 40(48.78)$ \\
\hline
\end{tabular}




\begin{tabular}{|c|c|c|c|c|c|c|c|c|c|}
\hline \multirow[t]{3}{*}{ Characteristics } & \multirow[t]{3}{*}{ Total } & \multicolumn{4}{|c|}{ BMI Category } & \multirow{2}{*}{$\begin{array}{c}P \\
\text { value }\end{array}$} & \multicolumn{2}{|c|}{ WC Category } & $P$ \\
\hline & & Underweight & Normal & Overweight & Obese & & Normal & Abdominal & value \\
\hline & & $(\mathrm{N}, \%)$ & $\begin{array}{l}\text { weight } \\
(\mathrm{N}, \%)\end{array}$ & $(\mathrm{N}, \%)$ & $(\mathrm{N}, \%)$ & & $(\mathrm{N}, \%)$ & $\begin{array}{l}\text { obesity } \\
(\mathrm{N}, \%)\end{array}$ & \\
\hline
\end{tabular}

\begin{tabular}{llllll}
\hline $420 \sim$ & 181 & $5(2.76)$ & $85(46.96)$ & $72(39.78)$ & $19(10.50)$
\end{tabular}

Stroke severity

\begin{tabular}{|c|c|c|c|c|c|c|c|}
\hline Mild disability & 486 & $22(4.53)$ & $240(49.38)$ & $170(34.98)$ & $54(11.11)$ & $0.016225(46.30) 261(53.70)$ & 0.617 \\
\hline Severe/Moderate & 268 & $27(10.07)$ & $135(50.37)$ & $84(31.34)$ & $22(8.21)$ & $119(44.40) 149(55.60)$ & \\
\hline
\end{tabular}

Family history of

stroke

\begin{tabular}{|c|c|c|c|c|c|c|}
\hline No & 606 & $39(6.44)$ & $312(51.49)$ & $200(33.00)$ & $55(9.08)$ & $0.143290(47.85) 316(52.15)$ \\
\hline Yes & 148 & $10(6.76)$ & $63(42.57)$ & $54(36.49)$ & $21(14.19)$ & $54(36.49) \quad 94(63.51)$ \\
\hline
\end{tabular}

Hypertension

\begin{tabular}{|c|c|c|c|c|c|c|}
\hline No & 284 & $25(8.80)$ & $157(55.28)$ & $86(30.28)$ & $16(5.63)$ & $0.001155(54.58) 129(45.42)<0.001$ \\
\hline Yes & 470 & $24(5.11)$ & 218(46.38) & $168(35.74)$ & $60(12.77)$ & 189(40.21) 281(59.79) \\
\hline
\end{tabular}

Diabetes mellitus

\begin{tabular}{|c|c|c|c|c|c|c|}
\hline No & 552 & $42(7.61)$ & 294(53.26) & 166(30.07) & $50(9.06)$ & $<.0001280(50.72) 272(49.28)<.0001$ \\
\hline Yes & 202 & $7(3.47)$ & $81(40.10)$ & $88(43.56)$ & $26(12.87)$ & $64(31.68) 138(68.32)$ \\
\hline
\end{tabular}

Hyperlipidemia*

\begin{tabular}{|c|c|c|c|c|c|c|}
\hline No & 486 & $41(8.44)$ & $269(55.35)$ & $140(28.81)$ & $36(7.41)$ & $<.0001248(51.03) 238(48.97)<.0001$ \\
\hline Yes & 266 & $8(3.01)$ & 104(39.10) & $114(42.86)$ & $40(15.04)$ & $94(35.34) 172(64.66)$ \\
\hline
\end{tabular}

Heart disease

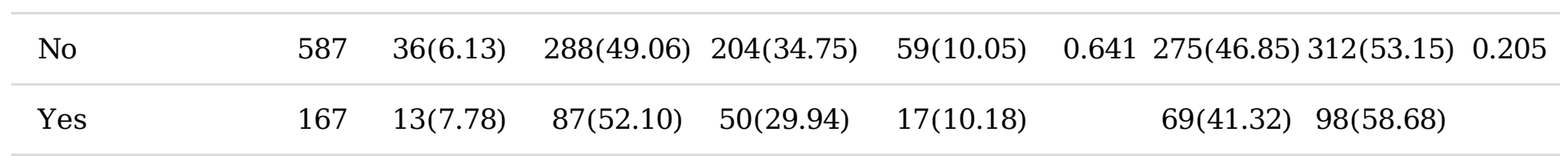

Peripheral vascular

diseases* $^{*}$

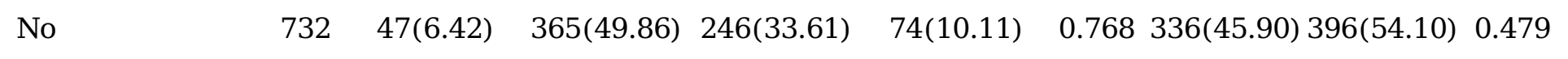




\begin{tabular}{|c|c|c|c|c|c|c|c|c|c|}
\hline \multirow[t]{5}{*}{ Characteristics } & \multirow[t]{5}{*}{ Total } & \multicolumn{4}{|c|}{ BMI Category } & \multirow{5}{*}{$\begin{array}{c}P \\
\text { value }\end{array}$} & \multicolumn{2}{|c|}{ WC Category } & \multirow{5}{*}{$\begin{array}{c}P \\
\text { value }\end{array}$} \\
\hline & & Underweight & Normal & Overweight & Obese & & Normal & Abdominal & \\
\hline & & & weight & $(\mathrm{N}, \%)$ & $(\mathrm{N}, \%)$ & & WC & obesity & \\
\hline & & & & & & & & $(\mathrm{N}, \%)$ & \\
\hline & & & $(\mathrm{N}, \%)$ & & & & $(\mathrm{N}, \%)$ & & \\
\hline Yes & 21 & $2(9.52)$ & $9(42.86)$ & $8(38.10)$ & $2(9.52)$ & & $8(38.10)$ & $13(61.90)$ & \\
\hline
\end{tabular}

Anti-thrombotic

drug medication

adherence

\begin{tabular}{|c|c|c|c|c|c|c|c|}
\hline Adherence & 306 & $18(5.88)$ & $156(50.98)$ & $99(32.35)$ & $33(10.78)$ & $0.804138(45.10) 168(54.90)$ & 0.811 \\
\hline Non-adherence & 448 & $31(6.92)$ & $219(48.88)$ & $155(34.60)$ & $43(9.60)$ & $206(45.98) 242(54.02)$ & \\
\hline
\end{tabular}

$C I$, confidence interval; $H R$, hazard ratio; $P$ by c2 test or Fisher exact test

${ }^{*}$ For some socio-demographic characteristics the sample size did not add up to 754 due to missing value

Table 2. Relationship between BMI, WC and aforementioned factors with all-cause mortality in unadjusted

analysis 
BMI criteria

Normal weight (18.5 to <23.9)

1.000 (reference)

Underweight $(<18.5)$

$1.554 \quad(0.895,2.700) \quad 0.118$

Overweight (24.9 to <27.9)

0.456

$(0.272,0.764) \quad 0.003$

Obese $\left(\geq 28.0 \mathrm{~kg} / \mathrm{m}^{2}\right)$

0.370

$(0.148,0.921) \quad 0.033$

WC criteria

Normal WC (male and WC $\leq 85 \mathrm{~cm}$ or female WC $\leq 80 \mathrm{~cm}$ )

1.000 (reference)

Abdominal obesity(male and $\mathrm{WC}>85 \mathrm{~cm}$ or female $\mathrm{WC}>80 \mathrm{~cm}$ )

0.527

$(0.352,0.790) \quad 0.002$

Gender

Male

1.000 (reference)

Female

1.125

$(0.756,1.674) \quad 0.561$

Age-group (year) ${ }^{*}$

$<45$

45

65
1.000 (reference)

$\begin{array}{lll}2.403 & (0.734,7.860) & 0.147 \\ 5.501 & (1.729,17.498) & 0.004\end{array}$

Marital status

\section{Without spouse}

With spouse
1.000 (reference)

0.455

$(0.287,0.719) \quad 0.001$

Education attainment (year)*

$\begin{array}{lccc}\leq 6 & 1.000 \text { (reference) } & \\ 7 \text { to } 9 & 0.446 & (0.258,0.770) & 0.004 \\ \geq 10 & 0.554 & (0.352,0.871) & 0.011\end{array}$

Occupation $^{*}$

Farmer

1.000 (reference)

Non-agricultural laborer

0.265

$(0.126,0.555)<0.001$

Retired

0.970

$(0.626,1.505) \quad 0.894$

Unemployed

0.678

$(0.283,1.621) \quad 0.382$ 


\begin{tabular}{clll}
\hline Parameter & $H R$ & $95 \%$ CI & $P$ value \\
\hline
\end{tabular}

House hold income (dollars/year)*
$<3057.4$
1.000 (reference)
3057.4 to 6114.8
1.006
$(0.638,1.587) \quad 0.980$
$>6114.8$
0.824
$(0.497,1.366) \quad 0.452$

Number of resident population

\begin{tabular}{lcccc}
$<3$ & 1.000 (reference) & & \\
\hline 3 to 4 & 0.716 & $(0.45,1.138)$ & 0.157 \\
\hline$>4$ & 0.886 & $(0.53,1.482)$ & 0.646
\end{tabular}

Smoking status

Non-smoking

Passive smoking

Smoking cessation

Current smoking

Drinking status

Non-drinking

Current drinking

Pre-stroke exercise time within one week (minutes)

\begin{tabular}{lccc}
$<210$ & 1.000 (reference) & & \\
\hline $210 \sim$ & 1.030 & $(0.546,1.944)$ & 0.928 \\
\hline $420 \sim$ & 0.750 & $(0.442,1.273)$ & 0.286
\end{tabular}

1.000 (reference)

\begin{tabular}{lll}
0.593 & $(0.324,1.085)$ & 0.090 \\
\hline 0.600 & $(0.377,0.955)$ & 0.031 \\
\hline 0.617 & $(0.247,1.542)$ & 0.302
\end{tabular}

1.000 (reference)

$0.603 \quad(0.386,0.943) \quad 0.027$

Stroke severity

Mild disability

Severe/Moderate disability

Family history of stroke
No
Yes
1.000 (reference)
$0.708 \quad(0.415,1.209) \quad 0.206$

1.000 (reference)
4.155
$(2.767,6.239)<0.001$

Hypertension 


\begin{tabular}{lcccc}
\hline & Parameter & $H R$ & $95 \% C I$ & $P$ value \\
\hline No & 1.000 (reference) & & \\
\hline Yes & 0.890 & $(0.595,1.330)$ & 0.569
\end{tabular}

Diabetes mellitus

\begin{tabular}{lccc}
\hline No & \multicolumn{3}{c}{1.000 (reference) } \\
\hline Yes & 1.158 & $(0.752,1.785)$ & 0.505
\end{tabular}

Hyperlipidemia*

\begin{tabular}{|c|c|c|c|}
\hline No & 1.000 (reference) & & \\
\hline Yes & 0.683 & $(0.445,1.049)$ & 0.081 \\
\hline
\end{tabular}

Heart disease

\begin{tabular}{lccc}
\hline No & \multicolumn{3}{c}{1.000 (reference) } \\
\\
Yes & 1.387 & $(0.896,2.147)$ & 0.142
\end{tabular}

Peripheral vascular diseases*

\begin{tabular}{lccc}
\hline No & 1.000 (reference) & \\
\hline Yes & 0.965 & $(0.306,3.043)$ & 0.951 \\
\hline Anti-thrombotic drug medication adherence & & & \\
\hline Adherence & 1.000 (reference) & & \\
\hline Non-adherence & 0.766 & $(0.512,1.147)$ & 0.196 \\
\hline
\end{tabular}

*For some socio-demographic characteristics the sample size did not add up to 754 due to missing values

Table 3. Effects of adjustment for personal characteristics and various indices of health on the association

between all-cause mortality and BMI criteria 


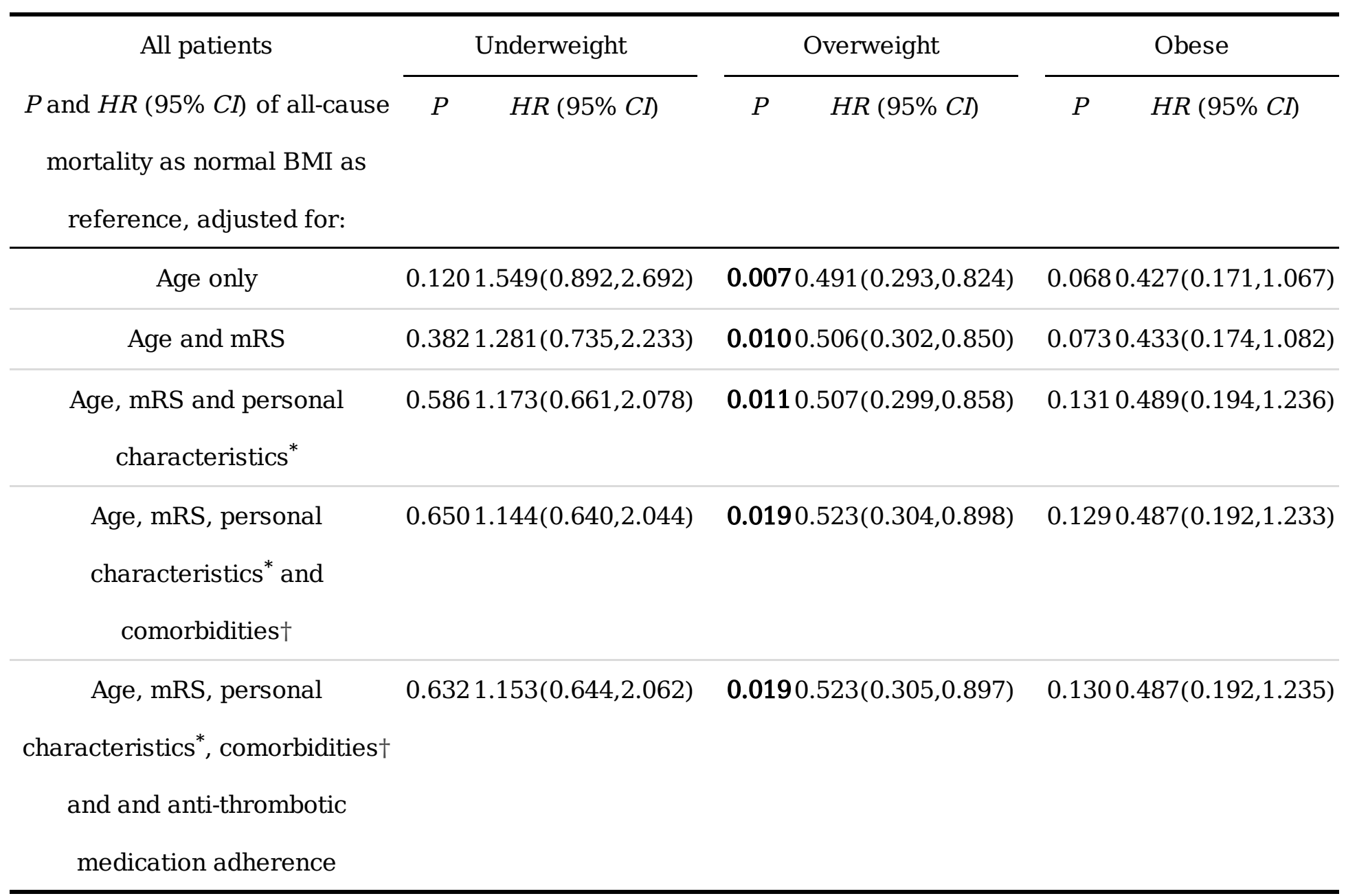

*personal characteristics include gender, civil status, occupation, education attainment, annual household income, number of resident population in their family, smoking status, drinking status, pre-stroke exercise time.

†Comorbidity included hypertension, diabetes mellitus, hyperlipidemia, heart disease, peripheral vascular diseases

Table 4. Effects of adjustment for personal characteristics and various indices of health on the association

between all-cause mortality and WC criteria 


\begin{tabular}{|c|c|c|}
\hline \multirow{2}{*}{$\begin{array}{c}\text { All patients } \\
P \text { and } H R(95 \% C I) \text { of all-cause mortality as normal WC as reference, adjusted for: }\end{array}$} & \multicolumn{2}{|c|}{ Abdominal obesity } \\
\hline & $P$ & $H R(95 \% C I)$ \\
\hline Age only & \multicolumn{2}{|c|}{$0.0030 .539(0.359,0.807)$} \\
\hline Age and $\mathrm{mRS}$ & \multicolumn{2}{|c|}{$0.0020 .528(0.352,0.793)$} \\
\hline Age, personal characteristics ${ }^{*}$ and $\mathrm{mRS}$ & \multicolumn{2}{|c|}{$0.0050 .547(0.360,0.832)$} \\
\hline Age, personal characteristics ${ }^{*}, \mathrm{mRS}$ and comorbidities $\dagger$ & \multicolumn{2}{|c|}{$0.0110 .569(0.368,0.880)$} \\
\hline $\begin{array}{c}\text { Age, personal characteristics* }{ }^{*} \text { mRS, comorbidities } † \text { and anti-thrombotic medication } \\
\text { adherence }\end{array}$ & \multicolumn{2}{|c|}{$0.0120 .572(0.370,0.883)$} \\
\hline
\end{tabular}

* personal characteristics include gender, civil status, occupation, education attainment, annual household income, number of resident population in their family, smoking status, drinking status, pre-stroke exercise time

†Comorbidity included hypertension, diabetes mellitus, hyperlipidemia, heart disease, peripheral vascular diseases.

\section{Figures}




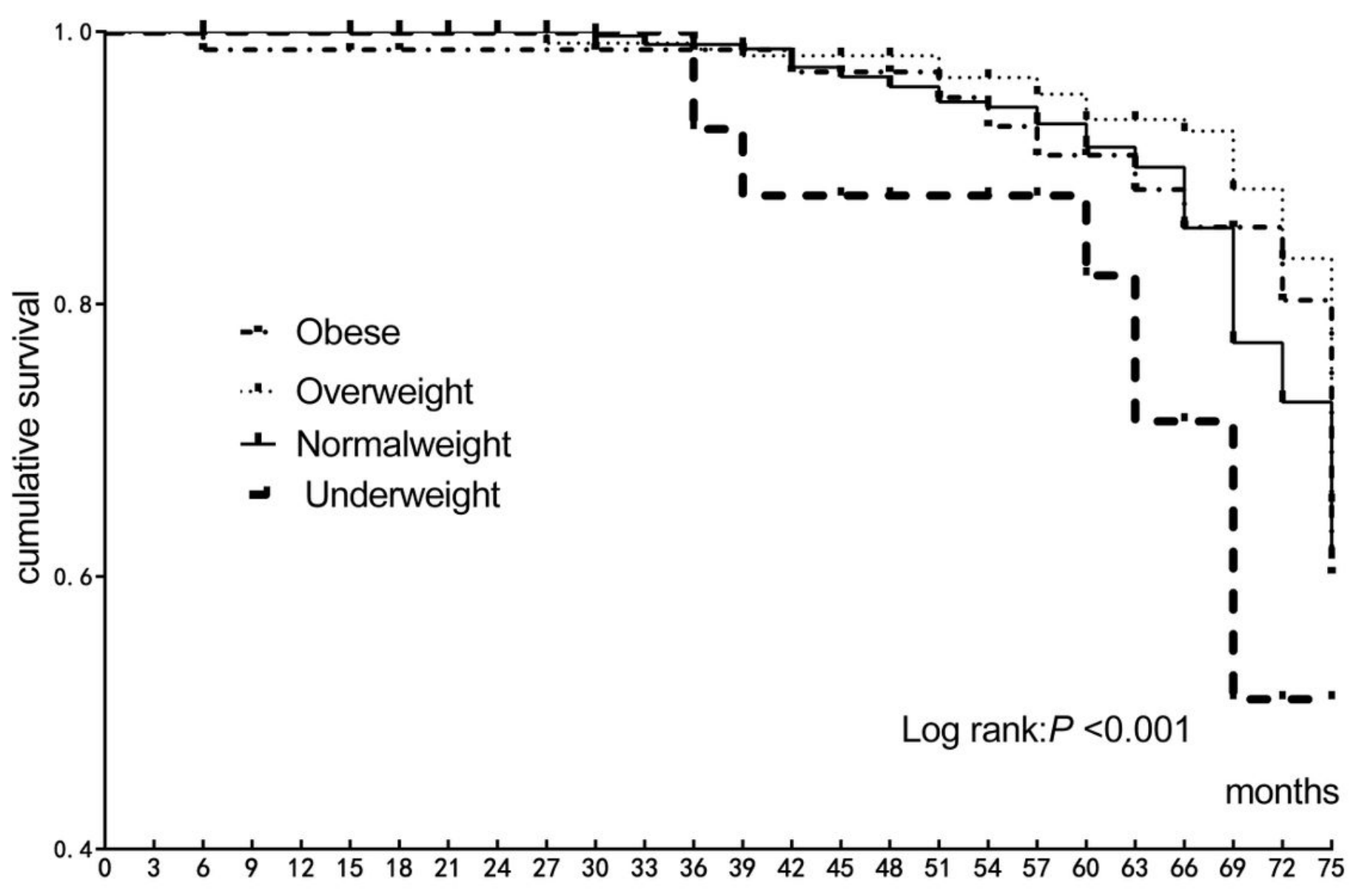

Figure 1

Survival curves after stroke according to groups of BMI (univariate analysis) 


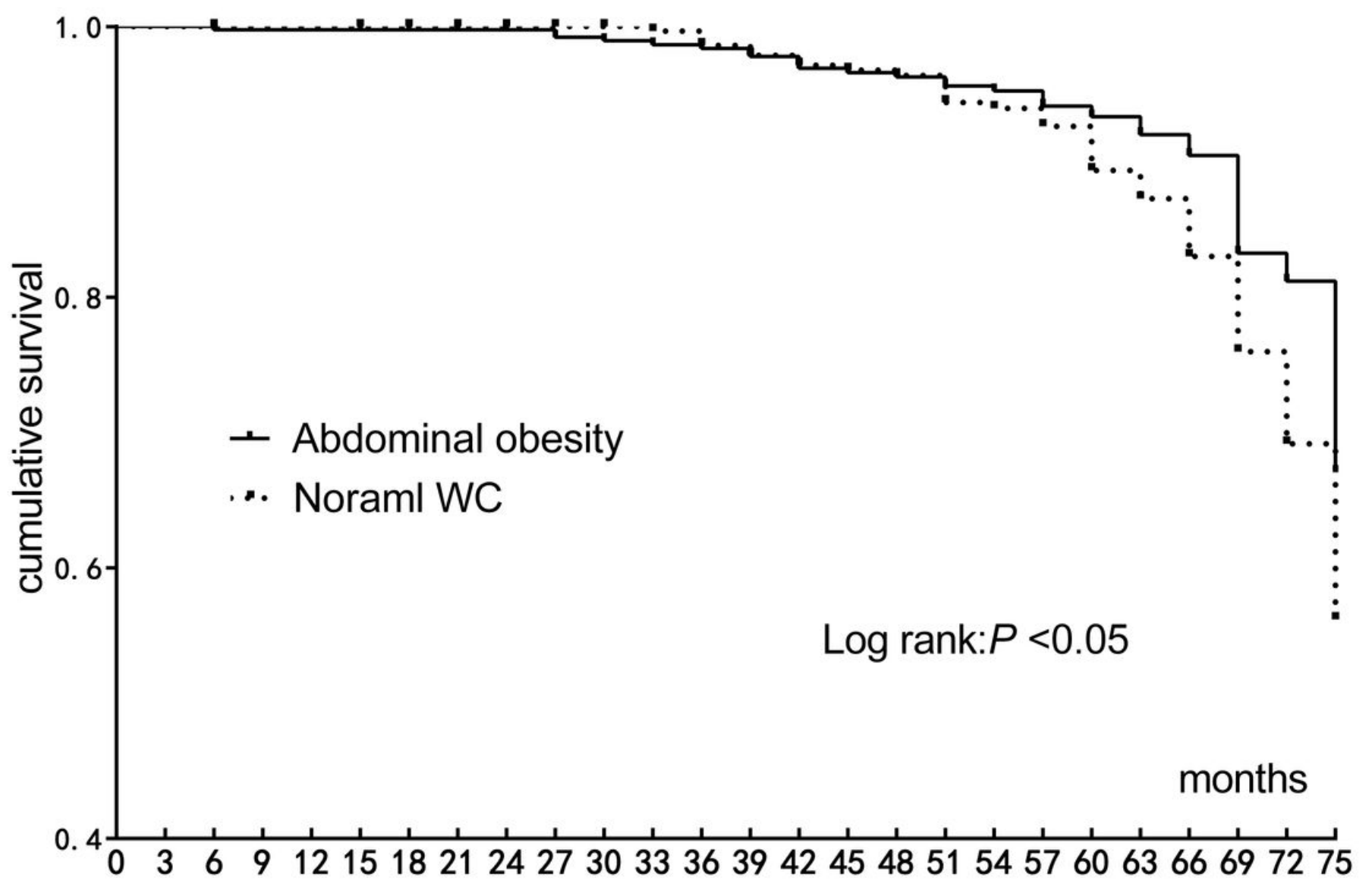

Figure 2

Survival curves after stroke according to groups of WC (univariate analysis) 